\section{Leadership by fragmented destruction after a merger: an example from a facility of acute psychiatry}

\author{
John E. Berg, Jorid Grimeland \\ Faculty of Health Sciences, Oslo \\ and Akershus University College, Oslo, \\ Norway
}

\section{Abstract}

Hospitals are labor intensive facilities based on highly skilled employees. A merger of hospitals is an effort to increase and rationalize this production. Decisions behind a merger are made at the top leadership level. How this might be done is demonstrated by examples from a 36 bed acute psychiatric facility. The aim of the study was to calculate the hidden costs of fragmented destruction of parts of a total hospital supply to patients after a merger. Fragmented destruction is the deliberate stopping of activities deemed not part of the core activities of the hospital without due consideration of the impact on core activities. The proposed changes to operational expenses at a single acute psychiatric hospital were materials for the study. The changes included activities as a reduction in local laboratory service, cleaning services, closure of physiotherapy unit, closing of cultural activities and reduced productivity. The selected activities are calculated as giving an imputed gain of $€ 630,000$ as indicated by the leadership. The not calculated costs of reducing or removing the selected activities are estimated at $€ 1,955,640$. The cost of staff disappointment after a merger is difficult to assess, but is probably higher than assumed in the present calculations.

Imputed cost containment is not attained. The calculations indicate that implemented changes may increase cost, contrary to the belief of the leadership at both the hospital level and further up in the hospital trust.

Arguments in favor of a merger have to be scrutinized thoroughly for optimistic neglect of uncalculated costs of mergers. Future hospital mergers and selected fragmentation of productive tasks at ward or hospital levels should include calculations of unavoidable costs as shown in the present paper.

\section{Introduction}

Health care has developed tremendously both in quantity and quality in all high-income countries. WHO states the time-frame for achieving the Millennium Development Goals by outlining a strategic framework and a platform for dialogue with partners in global health. ${ }^{1}$ WHO underscores the need for strong political will, good governance and wise leadership at all levels of a hospital chain. One would expect that a country like Norway follow these recommendations as a member state?

Principal agent theory postulates that the consumer of health care and the provider of health care are not able to value the advice given by doctors. Inferences about cost efficiency are accordingly less transparent to the parties. ${ }^{2}$ The theory describes the difficulties in motivating one party (the agent) to act on behalf of another (the principal) in a case where the two have differing interests and asymmetric information. In short only the doctor knows what the patient needs.

Modern leadership in health facilities is constrained by models demanding cost minimization without being able to monitor quality of the product, i.e. the improvements in health for the patients. The Scandinavian countries and Great Britain introduced some level of private supply to the National Health Service covering all citizens. Norway still uses the pay as you go principle, i.e. the Parliament grants and allocates a sufficient amount of money each year. What constitutes a sufficient amount is more a political than a health science related question.

\section{Mergers of hospitals}

Mergers of hospitals may be viewed as the forerunner of leadership by fragmented destruction at the single hospital level. Fragmented destruction is here defined as the deliberate stopping of activities deemed not part of the core activities of the hospital without due consideration of the impact on core activities.

Hospitals are employee-intensive firms in need of highly competent staff. In a country like Norway people live far from each other. Combining specialized high quality care with small units is hardly possible when the population demands comprehensive treatment and care within all of the diverse medical specialties. One way out of the conflict between quality and size would be by merging hospital services. Several studies shed light on this topic. In a summary Weil states: Hospital mergers have been done in Europe in order to reduce expenses, increase access to treatment and care and to augment the quality of the care given. Mergers are no guaranty of cost containment or increase in quality. Almost all mergers studied failed. The leaders of the hospitals lacked understanding and appreciation of differences in culture, values and aims of the original units. ${ }^{3,4}$ The author continues by stating that mergers will be started to increase the market position of
Correspondence: John E. Berg, Faculty of Health Sciences, Oslo and Akershus University College, Box 4 St. Olavsplass 0130, 0slo, Norway.

Tel. +47.2245.2000.

E-mail: john@pong.no

Key words: cost containment, hospital management, mergers, core activities.

Contributions: the authors contributed equally.

Conflict of interests: the authors declare no potential conflict of interests.

Received for publication: 7 July 2012.

Revision received: 7 September 2013.

Accepted for publication: 11 September 2013.

This work is licensed under a Creative Commons Attribution NonCommercial 3.0 License (CC BYNC 3.0).

(C)Copyright J.E. Berg and J. Grimeland., 2013

Licensee PAGEPress, Italy

Mental Illness 2013: 5:e11

doi:10.4081/mi.2013.e11

the hospital, reduce redundant capacity and to increase the ego of the leaders of the organizations. A somewhat more positive result of mergers is shown in a Danish study from 2010.5 The authors use Data Envelopment Analysis, DEA. They find large differences in technical efficiency between the merging hospitals, and as a result of this they find differing cost reductions. Exchanging best practice on specified tasks attains this. Some mergers result in the creation of very big units. Such large-scale units surpass the advantages according to standard productivity theory. The imputed boost in efficiency of this large unit is reduced and the merger costs may be substantial.

Kjekshus and Hagen studied seven mergers of 17 hospitals in Norway. ${ }^{6}$ They also employed the DEA method of calculating efficiency. There was no technical efficiency gain and cost efficiency was reduced from $4.8 \%$ to $2.8 \%$ in the different mergers. One of the mergers studied did give both technical and cost efficiency gains. Both administrative and acute functions were centralized. Thus they conclude that half-hearted mergers, where important functions are not centralized, do not attain the goal of cost containment, often the sole explicit reason for a merger.

In conclusion, mergers of hospitals under the prevailing premises are not economically sound. High cost is a rule, not an exception. Notwithstanding, a merger will inevitably be followed by demands for combining activities at all levels and a search for areas that may be outsourced or reduced or stopped.

Thus it would be of interest to study the 
effect of the adjustments proposed by the hospital leadership at ward and sub-ward levels after a merger of several hospitals.

\section{Materials and Methods}

The material for this study is extrapolated from interviews with health care workers in an acute 36 -bed psychiatric hospital and based on actual cost containment efforts. Calculations are made according to the relevant prices of services and procedures. The wages of staff before tax are used in the calculations. The calculations are based on actual expenses when service levels were changed or made unavailable. ${ }^{7}$

\section{Results}

\section{Reduction of laboratory services for wards situated at a distance from the main clinical laboratory}

i) A decision was made to reduce the presence of a bio-engineer at the psychiatric hospital from five to three days a week. Imputed gain for the hospital is calculated as 2/5 of the cost of a bio-engineer. The cost of running the satellite laboratory is not changed much as it is still used 3 days a week after the change. ii) Costs not included as laboratory costs: transport of patients in need of emergency or regular blood tests or ECGs to the main clinical laboratory, an expense connected to the activity of the laboratory, but not any more part of the budget of the laboratory. Eight patients a week $=416$ patients a year at a transport cost of $€$ 40 per visit. Variable cost of transporting psychotic, aggressive patients in need of laboratory testing with ambulance and/or police calculated at 10 patients a year at a cost of $€ 200$ for each transport. Thirty extra resident days accrues because of delay in treatment decisions at a calculated of $€ 800$ per day.

\section{Closure of physiotherapy services to psychiatric patients}

According to the Law of Psychiatric Services physiotherapeutic treatment is not a compulsory part of the running of a psychiatric hospital. Thus this activity may be stopped and the physiotherapists become redundant. The physiotherapy department has four employees with two main tasks: i) stimulating and surveying physical activity of patients. Such activities are proven to reduce bed occupancy and promote alleviation of symptoms; $;, 9$ ii) contributing to the diagnosis of difficult and unclear cases through examination of body posture, respiration and movements, a task involving methods from psychomotoric physiotherapy. ${ }^{10,11}$

Imputed gain of closing this department is set equal to the salaries, i.e. $4 \times 40,000 €=$ $160,000 €$. Not calculated costs of closure of the physiotherapy services are difficult to assess. A probable scenario would be to refer patients with uncertain diagnosis of psychosis to an extramural service provider for a second opinion evaluation by non-verbal means. This would incur a cost to the hospital of $€ 50$ per visit. A conservative estimate would be $5 \%$ of the resident patients $(\mathrm{N}=800$ /year) at five consultations each. Fourteen patients $\times 5 \times 50 €=$ $10,000 €$.

\section{Outsourcing of cleaning services}

When cleaning services are outsourced, the employees of the external firm have to follow the rules and quality requirements of that firm. These may be in conflict with what the health workers of the hospital expects. Complaints about the frequency or quality of cleaning services are not easily handled. At best this is an irritation and at its worst, none-settling of conflict may reduce the quality of health care given. High quality health workers may start changing defect light bulbs, supplying toilet paper and emptying the garbage bin in their offices themselves. The loss of productivity connected or loss of time is not calculated as a cost to the hospital.

A priori it is unsettled whether the hospital in fact save costs by outsourcing and paying for a similar service from an external firm. The value of regular contact between stable cleaning staff within house and patients and staff is not calculated.

\section{Cabaret or artistic activity for patients under the supervision of professional staff}

Inpatients in closed wards or outpatients with chronic severe mental disorders use their creative abilities in an understanding and rewarding atmosphere within an artistic activity connected to the hospital. This is not meant as a therapeutic activity. The route to the improvements through such activities among patients with mental health problems may be by restoring defect early object relations. 12 The imputed gain per year when the artistic activity for the patients is stopped and the professional employees are made redundant is $€$ 300,000 .

Ten of the 40 patients using the creative activity get a relapse to a worse condition. A mean of 60 extra inpatient days is calculated at $€ 800$ a day per patient, summing up to $€$ 480,000 . This cost, which is not calculated as such is in fact a cost to the same hospital connected to the imputed gain of $€ 300,000$.

\section{Reduced productivity of health workers}

The fragmented destruction of the activities of the hospital is a challenge for all employees. It is a general experience that down-sizing and major changes of work environment negatively influences the productivity of the workers..$^{13}$ Confidence in leadership is reduced and the meaningfulness of the work done is challenged. The health workers feel that what they do is no longer appreciated. Even if so, they may observe that the changes introduced reduces the possibility of success of the clinical work done and may increase the need for sick leave. The best soon leave the hospital.

This induces a lower productivity calculated here as $5 \%$ of the salary budget of the hospital. The total budget is $€ 31.6$ million and $90 \%$ of this is employment costs. Five per cent of $€$ 28.5 million (90\%) amounts to $€ 1,423000$.

Table 1 sums up the calculations above and the sum total is an imputed gain of $€ 630,000$ and not calculated costs at $€ 1,955,640$.

\section{Discussion and Conclusions}

The adjustments proposed by the leadership at a single hospital after a merger may have

Table 1. Yearly calculated imputed gain and costs with proposed changes after a merger of hospitals as seen at a single psychiatric facility.

\begin{tabular}{lll} 
Activity & $\begin{array}{l}\text { Imputed gain } \\
\text { per year }\end{array}$ & Not calculated costs \\
Local laboratory & $€ 20,000$ & $€ 16,640$ (transport of cooperating patients) \\
service at unit & & $€ 2000$ (10 transports of difficult patients) \\
& & $€ 24,000$ (30 extra hospital days for difficult patients) \\
Cleaning services & $€ 150,000$ & $?$ \\
\hline Closure of physiotherapy & $€ 160,000$ & $€ 10000$ \\
Cabaret & $€ 300,000$ & $€ 480,000$ \\
\hline Reduced productivity & $€ 0$ & $€ 1,423,000$ \\
Sum total & $€ 630,000$ & $€ 1,955,640$
\end{tabular}


unforeseen effects. Although mergers, changes of location and redistribution of staff may be necessary because of the development of medical technology and treatment paradigms, it is of importance that these adjustment achieve what they are supposed to. We have shown that this is not necessarily the case under a set of conservative assumptions. At first glance activities may be changed seemingly without any effect other than the reduction on the hospital budget. Table 1 and the explanations above illustrates that the reductions often results in an increase in costs either on another part of the hospital budget or at another point in the total health care chain. Estimating the not calculated costs may be difficult, as demonstrated for physiotherapy services, but this does not prove there are none. The imputed gain may on the other hand often be deemed greater than what is finally achieved because of labor security laws and decision delays.

A greater distance between leaders at several levels and health workers after a merger may establish a self-sufficient, top-down paranoid thinking leadership that considers any criticism or alternative organizational steps as tokens of irresponsible and non-conform acts. Such systems of loyalty were the hallmarks of former Soviet Union and its vassal states (personal communication, Psychiatrist Asbjørn Restan).

Such destructive leadership decisions fragments care and make health care workers less dedicated to their work. Preoccupation with the changes introduced, firstly to understand them, and secondly often to try to counter the changes, takes time in any industry. ${ }^{14}$ Time is also used to find out whether another employer might give better conditions for work. This all reduces quality and efficiency of the hospital. The calculated five per cent reduction in productivity is considered a low estimate of the effect of leadership by fragmented destruction.

Down-sizing may be performed so that each resource is treated separately, increasing some and decreasing others, and according to a plan combining this to better operational performance. This has been tried out in emergency departments. ${ }^{13}$ It is finally an open question why leaders at hospital level perform so incoherent and attain dismal economic results and disrupts cooperation in the hospital.

\section{References}

1. WHO. Framework for action on interprofessional education \& collaborative practice. 2010. Available from: http://whqlibdoc.who.int/hq/2010/WHO_HRH_HPN_10. 3_eng.pdf.

2. Jones A. Hospital care pathways for patients with schizofrenia. J Clin Nurs 2001;10:58-69.

3. Weil T. Hospital mergers: a panacea? J Health Serv Res Policy 2010;15:251-3.

4. Weil T. Hospital consolidations: do they deliver? Physician Exec 2010;36:24-7.

5. Kristensen T, Bogetoft P, Pedersen K. Potential gains from hospital mergers in
Denmark. Health Care Manag Sci 2010;13:334-45.

6. Kjekshus L, Hagen T. Do hospital mergers increase hospital efficiency? Evidence from a National Health Service country. J Health Serv Res Pol 2007;12:230-5.

7. Kaa E. Street drugs in Denmark. Forensic Sci 1991;36:866-79.

8. Martinsen E. Physical activity in the prevention and treatment of anxiety and depression. Nordic J Psychiatry 2008;62 Suppl 47:25-9.

9. Martinsen E, Medhus A, Sandvik L. Effects of aerobic exercise on depression: a controlled study. Br Med J 1985;291:109.

10. Houge N. Physiotherapy in certain aspects of psychosomatic medicine. Psychother Psychosom 1979;32:302-5.

11. Bülow-Hansen A, Houge N. [Cooperation between a physiotherapist and a physician in connection with psychomotor physiotherapy]. Tidsskr Nor Legeforen 1990;110:3498-500. [Article in Norwegian].

12. Oppenheim L. A curious intimacy. Art and neuro-psychoanalysis. New York: Routledge; 2005.

13. Duffield C, Kearin M, Johnston J, Leonard J. The impact of hospital structure and restructuring on the nursing workforce. Aust J Adv Nurs 2007;24:42-6.

14. Karasek R. Labor participation and work quality policy: requirements for an alternative economic future. Work Environ Health 1997;23 Suppl 4:55-65. 